\title{
Search for temporal changes in the velocity of Ice Stream B, West Antarctica
}

\author{
J. MaDonald AND I. M. Whillans \\ Byrd Polar Research Center and Department of Geological Sciences, The Ohio State University, \\ Columbus, Ohio 43210, U.S.A.
}

\begin{abstract}
The position of the UpB camp on Ice Stream B, West Antarctica, has been measured 14 times during three field seasons. TRANSIT (doppler) satellite receivers were used. At the resolution of our measurements $(2 \mathrm{~m})$, no significant velocity variation was detected over time intervals ranging from $1 \mathrm{~d}$ to 2 years.
\end{abstract}

\section{INTRODUGTION}

Prior studies have shown that there are time variations in the velocity of the Ross Ice Shelf and vicinity. The central part of the Ross Ice Shelf shows a possible increase in velocity over a 9-11 year interval (Thomas and others, 1984). Also, Ice Stream B, just before it enters the Ross Ice Shelf, has slowed down over an 11 year period (Stephenson and Bindschadler, 1988). It may be anticipated that there are comparable changes in Ice Stream B, up-glacier of these sites, and moreover that there are velocity changes over shorter time intervals.

In this study, the motion of a single marker (station 01, at the UpB camp; Fig. 1) is analysed. The average speed of this marker is $446.7 \pm 0.2(1 \sigma) \mathrm{m} \mathrm{a}^{-1}$ (determined by this study for a 2 year interval). The TRANSIT or doppler satellite positioning system is used, and the rate of displacement of the marker is studied for time variation.

The measurements involve tracking transmissions from passing TRANSIT (also called doppler) satellites. The tracking data are recorded over periods ranging from 0.98 to $8.5 \mathrm{~d}$, one to nine times during each of three field seasons. JMR-1 and Magnavox MX-1502 satellite receivers are used. Positions are calculated from the recorded data using the best software available. Tracking data are omitted that contain less than ten satellite passes for which precision orbital data are available, as well as data that show time drift of the receiver oscillator. Fourteen separate quality positions are available (Table 1).

\section{DATA ANALYSIS}

The satellite-tracking data are reduced in point-positioning mode using GEODOP V software (Kouba, 1983). The calculations use precise orbits for up to five of the TRANSIT satellites, obtained from the U.S. Defense Mapping Agency. The recorded data are separated into time intervals that are less than $24 \mathrm{~h}$ in length, in order to ensure that the motion of the site during the recording period is less than twice the estimated $1 \mathrm{~m}$ r.m.s. error normally associated with the technique (Kouba, 1983). This software has been shown to perform well on ice sheets

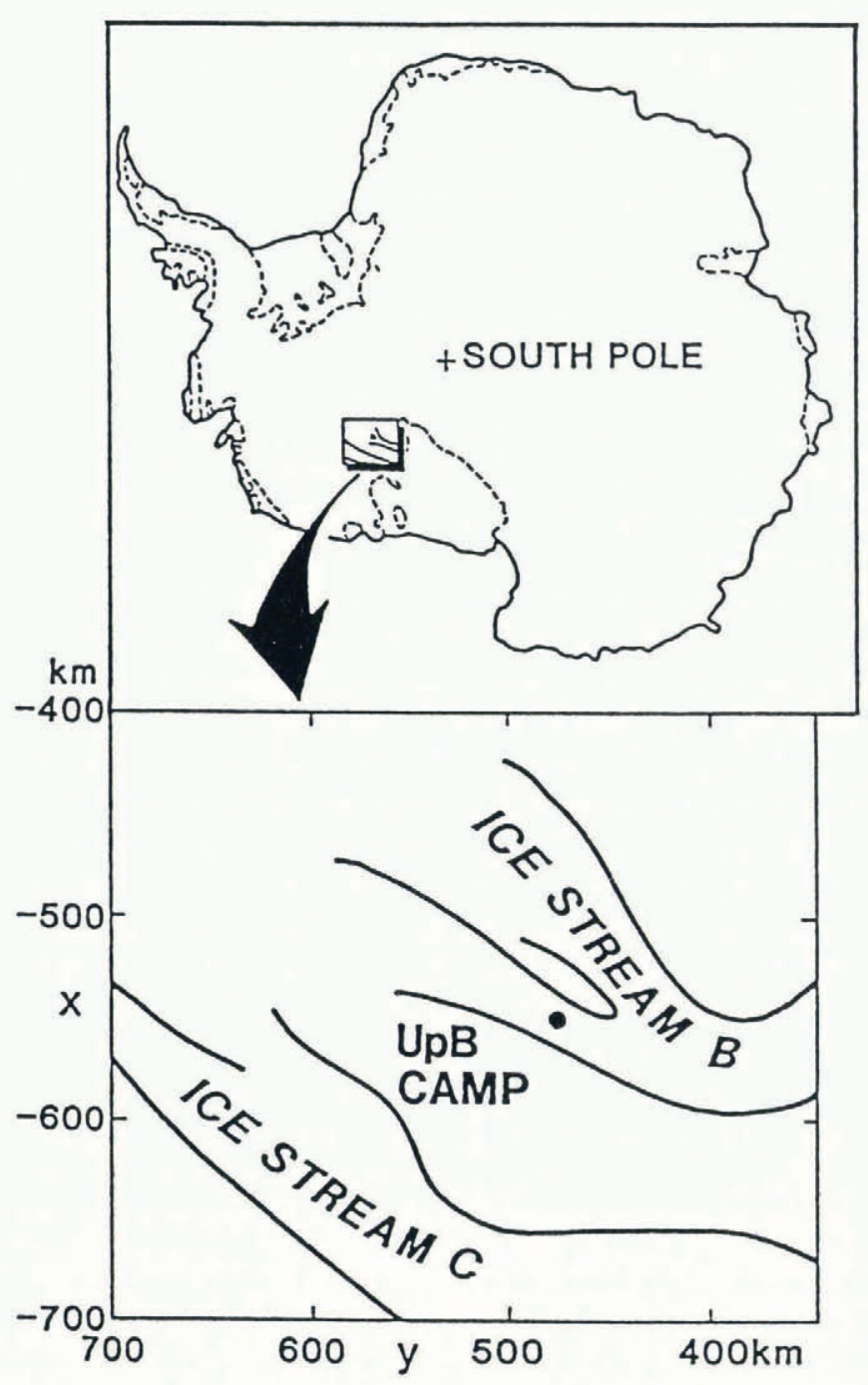

Fig. 1. The study site is on tributary B2 of Ice Stream B. 


\begin{tabular}{|c|c|c|c|c|c|c|}
\hline File name & $\begin{array}{c}-X \\
\mathrm{~m} \\
540000 \\
+\end{array}$ & $\begin{array}{c}r \\
\mathrm{~m} \\
480000 \\
+\end{array}$ & $\begin{array}{c}\text { Ellipsoidal } \\
\text { height } \\
\mathrm{m}\end{array}$ & $\begin{array}{l}\text { Year, day and time } \\
\text { of last pass in file }\end{array}$ & $\begin{array}{l}\text { Number of } \\
\text { passes used }\end{array}$ & $\begin{array}{c}\text { Formal error } \\
\text { m }\end{array}$ \\
\hline B301A & 1683.5 & 7296.4 & 339.8 & $1983-315-22: 46$ & 22 & 0.95 \\
\hline B301B & 1683.8 & 7295.8 & 337.8 & '83-317-00:48 & 22 & 0.84 \\
\hline B301C & 1684.7 & 7294.3 & 339.1 & '83-318-11:14 & 28 & 0.78 \\
\hline B301D & 1688.2 & 7285.7 & 339.2 & '83-326-13:54 & 19 & 1.03 \\
\hline B301E & 1687.8 & 7282.5 & 338.4 & '83-327-14:52 & 27 & 0.89 \\
\hline $\mathrm{B} 301 \mathrm{~F}$ & 1689.3 & 7280.9 & 338.8 & '83-328-19:52 & 24 & 0.86 \\
\hline B301G & 1714.9 & 7238.7 & 339.8 & '84-004-02:24 & 28 & 0.76 \\
\hline $\mathrm{B} 301 \mathrm{H}$ & 1715.2 & 7238.1 & 340.6 & '84-004-23:46 & 18 & 1.07 \\
\hline B301I & 1715.9 & 7235.6 & 339.1 & '84-007-21:48 & 30 & 0.77 \\
\hline B400 & 1914.2 & 6873.9 & 340.5 & '84-345-15:36 & 14 & 1.09 \\
\hline B501 & 2129.8 & 6478.6 & 342.8 & '85-346-23:32 & 15 & 1.00 \\
\hline B502 & 2130.5 & 6477.9 & 341.3 & $85-347-18: 22$ & 14 & 1.07 \\
\hline B5016 & 2130.3 & 6476.1 & 341.8 & '85-350-11:10 & 18 & 0.99 \\
\hline B5017 & 2134.3 & 6472.7 & 344.9 & '85-351-22:08 & 12 & 1.10 \\
\hline
\end{tabular}

(Drew and Whillans, 1984; McDonald and Whillans, 1988).

In other studies, TRANSIT data have been reduced using the network-adjustment technique (Drew and Whillans, 1984; Whillans and others, 1987; McDonald and Whillans, 1988; McDonald, 1990). Network calculations generally yield more precise relative positions by tying them to fixed reference sites. However, for the present study, the reference stations are not sufficiently stable or not always simultaneously occupied. Thus, the network technique cannot be used with all the data, and so, for consistency, the point-positioning technique is used throughout.

The resulting positions are analyzed for deviations from a 2 year trajectory. These deviations are shown in Figure 2. The long-term trajectory is based on positions near the beginning and end of the study.

The positions used to define the trajectory are selected based on the following five criteria (Kouba and Boal, 1976; McDonald, 1990, appendix A): (1) The value of the standard deviation of unit weight resulting from the calculation should be close to and a little less than unity. (2) The relative number of passes and doppler counts rejected in the calculations should be small. (3) The calculated time drift of the receiver oscillator should be linear. (4) The solution shows good convergence of the standard deviation of unit weight and of each coordinate position. (5) The number of tracked satellite passes with precision orbits should be large. These criteria are combined in a qualitative judgement to select the "best" positions and the long-term ice trajectory.

An alternative method for obtaining the trajectory would be to calculate a "least-squares" fit to all the positions. The positions would be weighted according to quality, with appropriate variances for each of the position components. Such a procedure is more difficult and would yield virtually the same result, especially if questionable data from days 327 and 328 in 1983 are omitted.

Figure 3 is a map of the positions of site 01 for three field seasons. The coordinate system has its origin at the South Pole with $x$-axis positive along $0^{\circ}$ longitude, and $y$ axis positive along $90^{\circ} \mathrm{W}$ longitude. The $x$-coordinate is defined by, $X=R \cos (\lambda)$, and the $y$-coordinate by, $r=$ $R \sin (\lambda)$, where $R=-r(\phi-\pi / 2)$. West longitude is represented by $\lambda$, and south latitude by $\phi$. The value of $r(=6398719.29 \mathrm{~m})$ is the average radius of the Earth between $82^{\circ}$ and $85^{\circ} \mathrm{S}$ on the WGS72 ellipsoid ( $A=$ $6378135.00 \mathrm{~m}, 1 / f=298.2597)$. The long-term ice trajectory (in $\mathrm{m}$ ) is $\{X=-541684.70-0.5863 t\},\{r=$ $487294.33-1.0738 t\}$, for time, $t$, in days since 14 November 1983. The r.m.s. deviation of the positions not used in defining the trajectory is $1.12 \mathrm{~m}$, and $0.80 \mathrm{~m}$ if the three suspect positions discussed below are excluded.

\section{ERRORS}

In the figures, the error bars represent twice the formal error of the adjustment for position. Inspection of the figures shows that twice the formal errors fully account for the scatter, especially if the suspect positions in 1983 are omitted.

The formal error is the internally calculated standard deviation derived from the least-squares adjustment for the parameters describing the satellite orbits, clock parameters within the receiver, tropospheric and ionospheric delay, and antenna position. The formal errors decrease somewhat more slowly than the inverse of the 


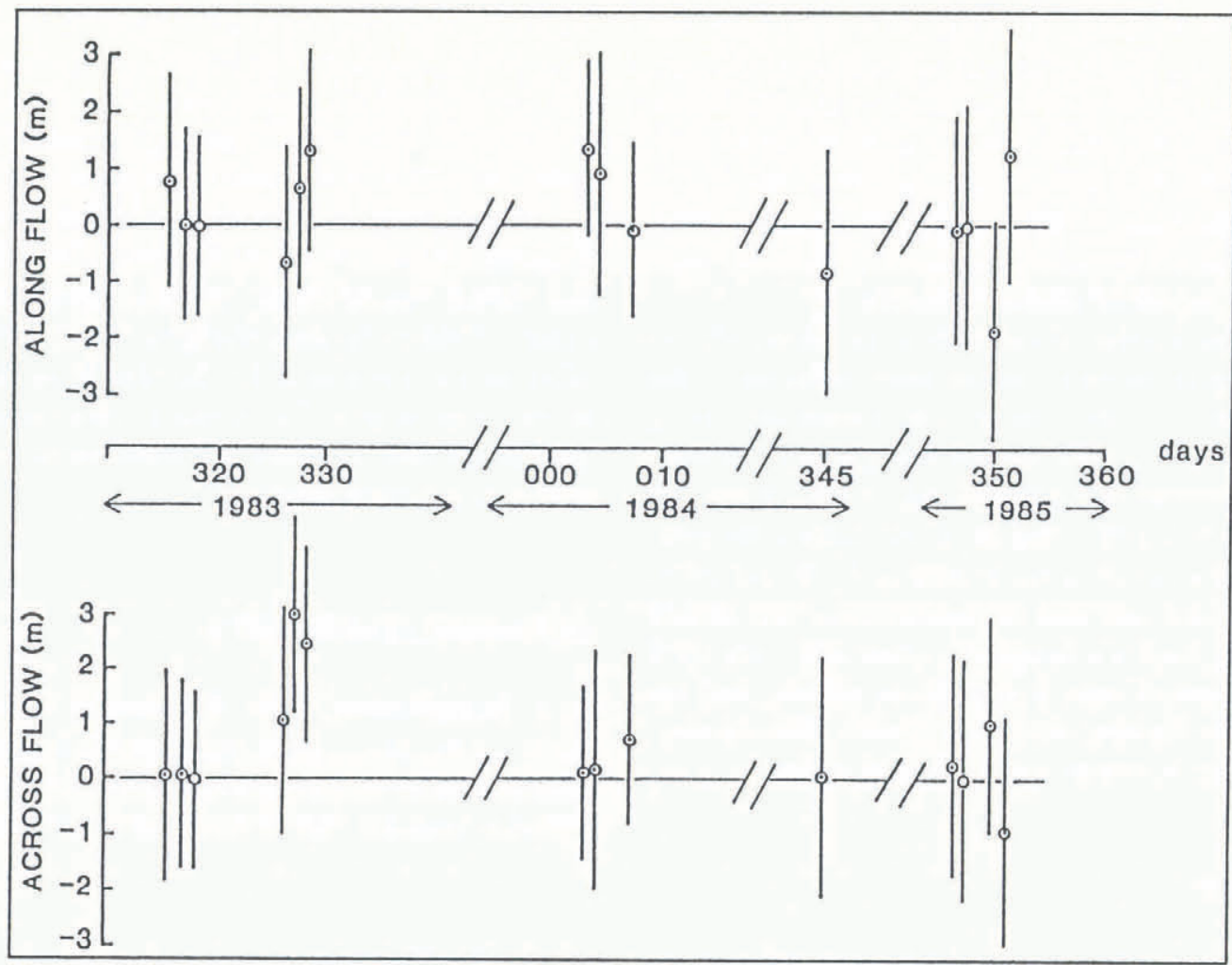

Fig. 2. Deviations ( $m$ ) from the 2 year trajectory plotted against fulian date (days). The vertical lines indicate twice the formal errors ( \pm 2 standard deviations). The reference trajectory passes through the two positions marked with open circles.

square root of the number of passes used in the solution. The slower decay arises because some errors, such as tropospheric delay, are not random over the $24 \mathrm{~h}$ or so of a tracking session (Kouba and Boal, 1976; Kouba, 1983; Shibuya, 1985).

Formal errors are usually considered to underestimate the uncertainty of the position because of unmodeled systematic errors. There may be a systematic error if the approximation used to model ionospheric refraction is inadequate (Anderle, 1985), and this would seem likely in polar regions. Also, over snow surfaces, the model used for the tropospheric delay may be inaccurate because of a near-surface temperature inversion. There are also systematic errors in satellite orbital parameters due to errors in the model for the Earth's gravity field. Some of these systematic errors may be nearly constant over intervals of 1 or $2 \mathrm{~d}$ (troposphere) or even from year to year (gravity field).
In earlier work, McDonald and Whillans (1988) found that the scatter or precision of positions is within the magnitude of twice the orbital error (twice $2 \mathrm{~m}$ r.m.s.; Kouba, 1983), which is a more pessimistic measure of precision than the formal error used here. However, in the prior study fewer passes were used, and so the random component of the orbital error cancelled less completely (Jenkins and LeRoy, 1979; McDonald, 1990). That measure of precision is probably fair for such quality of data.

In the present study there are more passes for each position, and the smaller formal errors (about $1 \mathrm{~m}$, r.m.s.) more nearly describe the scatter than does the orbital error (2 m, r.m.s.).

Exceptions to the small scatter occur on days 327 and 328 of 1983. There is reason to doubt the positions for these days. The data were first sent to the U.S. Defense Mapping Agency. (DMA), who could not obtain a

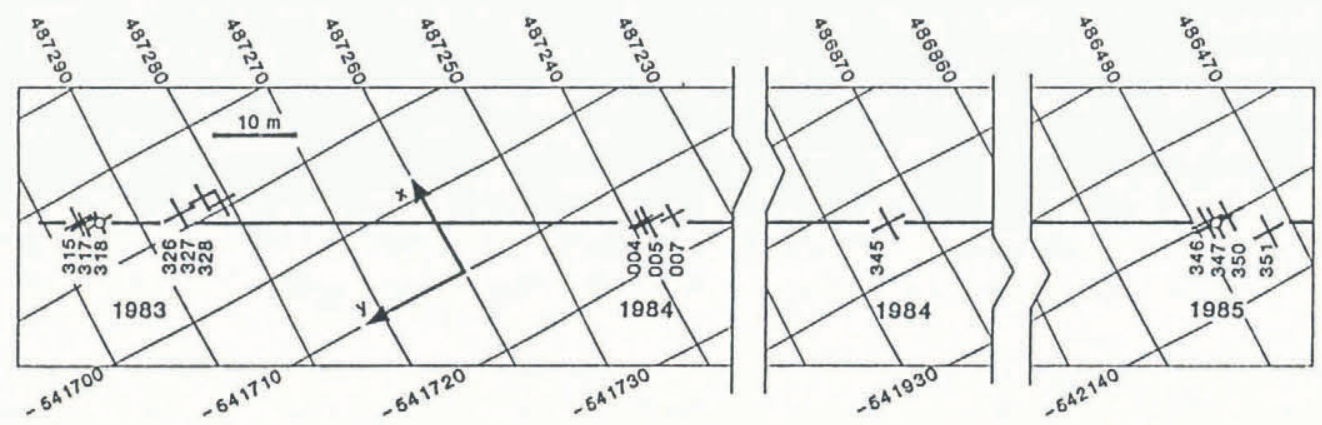

Fig. 3. Map view of positions. The associated numbers are Julian dates. 
solution for these 2 days or for day 326 . However, the software used in this study obtained normal and adequate solutions for these positions. A possibility is that the DMA software incorrectly distributes errors, with the result that mismatches accumulate around certain parameters, thus leading to the rejection of data. Alternatively, the DMA software may have special rejection criteria. We were unable to learn details of DMA's software.

Velocity calculated from positions obtained on successive days may be more precise than otherwise. This may arise because precise orbits are calculated using tracking data covering $48 \mathrm{~h}$ time spans (Anderle, 1976). Thus, precise orbits for neighboring days should be somewhat covariant and a degree of correlation between positions for consecutive days is expected. If this effect were important, the positions for consecutive days should deviate together from the long-term trajectory. Any such tendency in Figures 2 and 3 is weak or absent, and we conclude, as have Kouba and Wells (1976), that the dayto-day covariance in orbits is not a strong effect.

\section{CONCLUSIONS}

Inspection of the graphs for the speeds (Fig. 2) and the graph of the trajectory (Fig. 3) shows that there is no significant variation in either the speed or direction of ice motion.

On an annual basis, the speed varies by less than about $0.4 \%$ (Fig. 2). This is remarkably constant, and contrasts with the down-glacial part of Ice Stream B, which has reduced speed by $20 \%$ over 10 years, or about $2 \%$ per year (Stephenson and Bindschadler, 1988). It seems that the slow-down at the mouth of Ice Stream B is unrelated, or is not yet related to the speed at $\mathrm{UpB}$, in the upper part of the ice stream.

Precision is relatively poor for short-term variations. For example, for a $3 \mathrm{~d}$ interval, days 004, 005 and 007 in 1984 , the deviation in speed from the long-term value is $135 \mathrm{~m} \mathrm{a}^{-1}$ or $30 \%$, but variations in the range of $0-120 \%$ are consistent with $2 \sigma$ errors. However, at a nearby site, Harrison and Echelmeyer (1989) did better precision work during a 5 week interval and found no significant speed fluctuations for time-scales as short as $1 \mathrm{~h}$. On a $12 \mathrm{~h}$ basis, their survey precision is $\pm 25 \mathrm{~m} \mathrm{a}^{-1}$ or $6 \%$, and on an hourly basis is $\pm 130 \mathrm{~m} \mathrm{a}^{-1}$ or $30 \%$. Together, the present work and that of Harrison and Echelmeyer indicate that there are no fluctuations at the hourly to annual scales.

Apparent temporal velocity variations can arise from advection of the station through a region with a non-zero strain rate. This effect is small. The longitudinal strain rate measured over distances of about $1000 \mathrm{~m}$ is about $0.001 \mathrm{a}^{-1}$ (paper in preparation by I. M. Whillans and C.J. van der Veen). The corresponding velocity change is about $0.45 \mathrm{~m} \mathrm{a}^{-1}$. This is too small to be resolved here, and no advective effect is to be expected.

Large changes in velocity occur on many glaciers, at many time-scales, including the scales resolvable here. The usual opinion is that these fluctuations are due to changes in basal meltwater amount or pressure. These can fluctuate due to changing supply and drainage. In particular, temperate glaciers experience enormous variations in surface-water supply. For Ice Stream B, no water is supplied from the upper surface, and water production is due to the more nearly constant effects of geothermal and frictional heats. The present result helps support the view that varying penetration of surface meltwater to the bed is indeed important to other glaciers.

Glacier motion can also be affected by changes in the drainage of basal mud, or by some creep instability that may affect lateral drag, vertical shear or longitudinal stresses. Evidently, such changes, if they occur, have little effect on the motion of Ice Stream B on the annual and shorter time-scales. The present negative results place a limit to the rate at which the basal lubricant or creep can vary in important ways.

\section{ACKNOWLEDGEMENTS}

R. A. Bindschadler, K. A. Echelmeyer and C.J. van der Veen made many good suggestions. Supported by U.S. National Science Foundation grant DPP-8716447. Contribution number 757 of the Byrd Polar Research Center.

\section{REFERENCES}

Anderle, R.J. 1976. Point positioning using precise ephemeris. In Proceedings of the First International Symposium on Satellite Doppler Positioning. Las Cruces, NM, New Mexico State University. Physical Science Laboratory, 47-58.

Anderle, R.J. 1985. Transition from NAVSAT to GPS geodesy. In Proceedings of the First International Symposium on Precise Positioning with the Global Positioning System: Positioning with GPS - 1985, 11-22.

Drew, A. R. and I. M. Whillans. 1984. Measurement of surface deformation of the Greenland ice sheet by satellite tracking. Ann. Glaciol., 5, 51-55.

Harrison, W. D. and K. A. Echelmeyer. 1989. Short-term variations in the speed of Ice Stream B, Antarctica. Antarct. 7. U.S., 24(5), 81-82.

Jenkins, R.E. and C. F. LeRoy. 1979. "Broadcast" versus "precise" ephemeris - apples and oranges. In Proceedings of the Second International Symposium on Satellite Doppler Positioning. Austin, TX, University of Texas at Austin. Applied Research Laboratory, 39-62.

Kouba, J. 1983. A review of geodetic and geodynamic satellite Doppler positioning. Rev. Geophys. Space Phys., $21(1), 27-40$.

Kouba, J. and J.D. Boal. 1976. Program GEODOP. Ottawa, Department of Energy, Mines and Resources.

Kouba, J. and D. E. Wells. 1976. Semi-dynamical Doppler satellite positioning. Bull. Geod., 50(1), 27-42.

McDonald, J. 1990. The use of TRANSIT satellites to study the West Antarctic ice sheet. (M.S. thesis, Ohio State University.)

McDonald, J. and I. M. Whillans. 1988. Comparison of results from Transit satellite tracking. Ann. Glaciol., 11, 83-88.

Shibuya, K. 1985. Performance experiment of an NNSS positioning in and around Syowa Station, East Antarctica. 7. Phys. Earth, 33, 453-483.

Stephenson, S. N. and R. A. Bindschadler. 1988. Observed 
McDonald and Whillans: Changes in the velocity of Ice Stream B

velocity fluctuations on a major Antarctic ice stream. Nature, 334(6184), 695-697.

Thomas, R.H., D. R MacAyeal, D.H. Eilers and D. R. Gaylord. 1984. Glaciological studies on the Ross Ice Shelf, Antarctica, 1973-1978. Antarct. Res. Ser., 42, 2153.
Whillans, I. M., J. Bolzan and S. Shabtaie. 1987. Velocity of ice streams B and C, Antarctica. 7. Geophys. Res., 92(B9), 8895-8902.

The accuracy of references in the text and in this list is the responsibility of the authors, to whom queries should be addressed.

MS received 12 June 1990 and in revised form 19 September 1991 